\title{
LVI. On the determination of the latitude of a place by means of the transit instrument placed perpendicularly to the meridian. Communicated in a letter to Professor Schumacher, dated Königsberg, Feb. 2, 1824
}

\section{Professor Bessel}

To cite this article: Professor Bessel (1825) LVI. On the determination of the latitude of a place by means of the transit instrument placed perpendicularly to the meridian. Communicated in a letter to Professor Schumacher, dated Königsberg, Feb. 2, 1824, Philosophical Magazine Series 1, 65:325, 354-357, DOI: 10.1080/14786442508652877

To link to this article: http://dx.doi.org/10.1080/14786442508652877

曲 Published online: 27 Jul 2009.

Submit your article to this journal $\pi$

ЦIl Article views: 2 
it would amply repay the labour. I must apologize to your readers for the mistakes which will be found in the investigation. I already see several which it is impossible now to correct. I have been forced to draw it up during moments of leisure snatched now and then from the toils of a laborious employment, and of a host of other less congenial though more necessary pursuits. Let this stand for my excuse. Detached and fragmentical as it is, I hope that my leading purpose is in some degree accomplished. The general inquiry, however, into the decomposition of $B_{z}$ is much more interesting and more practically useful; and as soon as I can command sufficient time to commit to paper the substance of what exists in my imagination respecting it, I will lay it before you with my best ability.

April 15, 1825.

$\Sigma$.

LVI. On the Determination of the Latitude of a Place by Means of the Transit Instrument placed perpendicularly to the Meridian. By Professor Bessec. Communicated in a Letter to Professor Schumacher, dated Königsberg, Feb. 2, 1824.**

WHEN, in the year 1819, I saw you at Lauenburg, and remarked to you that it might be advantageous to determine the differences of the altitude of the pole (for the purpose of measuring geographical degrees) by means of a transit instrument, moving nearly perpendicular to the meridian, I had in view the difficulties often experienced in observing zenith distances. This difficulty is certainly removed by Ramsden's zenith sector, used in the English admeasurement of degrees for observing the differences of latitude, as well as by yourself and M. Gauss in your great undertaking of the same kind. It is also removed by the employment of Reichenbach's meridian circle for the purpose of measuring the zenith distances of stars passing near the zenith ; for it is with such stars that the instrument gives the correct results, without the investigation of other zenith distances. I do not wish to refuse the fullest confidence to such means for obtaining the differences of latitude: therefore any other proposal might at present appear superfluous.

But if we are desirous to obtain a certain degree of accuracy with much less trouble, or try the results already obtained by a different method, I have no doubt but that it might be effected by the method which I am about to propose. My intention is to avoid entirely the divisions of the circle, and

* From Schumacher's Astronomische Nachrichten, No. 49. 
to deduce the results by means of the watch; which I effect in the following manner.

I place a transit instrument (whose axis is horizontal, and whose line of collimation is correctly adjusted) so that the middle wire should describe a vertical circle. Its axis should lie nearly in the meridian, so that the vertical circle should stand. nearly east and west, and thus twice traverse the parallels of all the stars which culminate between the equator and zenith.

The observation of the two times $T$ and ' $T^{\prime}$ in which the star passes the wire of the telescope will give the altitude of the pole as well as the zenith distance of the star on the meridian; and by repeating this observation in another place we shall obtain the difference in the altitude of the pole, or zenith distance, almost independently of the assumed declination of the star. However, the tines $\mathrm{T}$ and $\mathrm{T}^{\prime}$ must be taken from a watch or clock which shows sidereal time: but it is not necessary that the correction of the clock, for the purpose of reducing it to the sidereal time, need be known.

In order to show the peculiarity of this method in a general view, I shall not take into account, at first, that the vertical circle described by the instrument is directed exactly east and west, but point out the results of, and the errors which might arise from, some elements of calculation, independently of that supposition.

I denote the correction of the clock by $\tau$ and $\tau^{\prime}$, taking them (as well as the observed times) in degrees, minutes and seconds; the right ascension and declination of the star by $\alpha$ and $\delta$; and the polar height by $\phi$. According to these designations the two hour angles of the star (negative if easterly) will be

$$
t=\mathrm{T}+\tau-\alpha \quad t^{\prime}=\mathrm{T}^{\prime}+\tau^{\prime}-\alpha
$$

and the cotangent of the azimuth will be

$$
=\frac{\cos t \cdot \cos \delta \cdot \sin \varphi-\sin \delta \cdot \cos \varphi}{\cos \delta \cdot \sin t}=\frac{\cos t^{\prime} \cdot \cos \delta \cdot \sin \varphi-\sin \delta \cdot \cos \varphi}{\cos \delta \cdot \sin t^{\prime}} \text {. }
$$

If we eliminate the azimuth from these two equations, we obtain

$$
\tan \varphi=\tan \delta \times \frac{\cos \left(\frac{t^{\prime}+t}{2}\right)}{\cos \left(\frac{t^{\prime}-t}{2}-\right)}
$$

or, by introducing the values of $t$ and $t^{\prime}$,

$$
\tan \varphi=\tan \delta \times \frac{\cos \left(\frac{T^{\prime}+t^{\prime}+T+t}{2}-\alpha\right)}{\cos \left(\frac{T^{\prime}+t^{\prime}-T-t}{2}\right)}
$$

If we now assume that $\delta, \alpha, \tau^{\prime}, \tau$ are incorrectly known, and require the corrections $d \delta, d \alpha, d \tau^{\prime}, d \tau$, we obtain thereby the correction of $\phi$ deduced from the formula just given, as under : 


$$
\begin{aligned}
d \varphi=d \delta & \cdot \frac{\sin 2 \phi}{\sin 2 \delta}+d \alpha \cdot \frac{1}{2} \sin 2 \phi \cdot \tan \frac{1}{2}\left(t^{\prime}+t\right) \\
& -d \tau \cdot \frac{\sin 2 \varphi \cdot \sin t^{\prime}}{2\left(\cos t^{\prime}+\cos t\right)}-\delta \tau^{\prime} \cdot \frac{\sin 2 \varphi \cdot \sin t}{2\left(\cos t^{\prime}+\cos t\right)}
\end{aligned}
$$

Let us now suppose that the instrument is correct to about a minute, moving from east to west; it is evident that the cosine may be placed $=1$, in the numerator of the result $(\tan \varphi)$ and we shall obtain

$$
\begin{aligned}
& \tan \varphi=\tan \delta \cdot \sec \frac{1}{2}\left(\mathrm{~T}^{\prime}+\tau^{\prime}-\mathrm{T}-\tau\right) \\
& d \varphi=d \delta \cdot \frac{\sin 2 \varphi}{\sin 2 \delta}+\frac{1}{4}\left(d \tau^{\prime}-d \tau\right) \sin 2 \varphi \cdot \tan \frac{1}{2}\left(\mathrm{~T}^{\prime}+\tau^{\prime}-\mathrm{T}-\tau\right)
\end{aligned}
$$

Whence it appears that an error in the difference of the correction of the time as shown by the clock (the influence of which is so much smalter, the smaller $T^{\prime}-T$ is, in the case in which this method is to be applied alone, viz. when the star culminates near the zenith) may be considered as trifling. Such an error would arise from the supposed incorrectness of the clock; but we may suppose that this is generally much better known than may be required in this method.

There remains, therefore, only the error of declination, which is

$$
d \varphi=d 8 \cdot \frac{\sin 2 \varphi}{\sin 2 \delta}
$$

For a star passing through the zenith, the altitude of the pole has exactly the same error as that of declination. For a star culminating south of the zenith, the error is greater; at least in our latitudes, Suppose this method were to be applied to determine the difference of latitude between two places, such as $51^{\circ}$ and $56^{\circ}$, and we were to select a star passing through the southernmost point of the zenith; the error in this point would be $=d \delta$; and in the northern place $=1.055 d \delta$. And the error in the difference of the polar alkitudes $=0.055 d \delta$; or even for $d \delta=2^{\prime \prime}$, only $0^{\prime \prime} \cdot 11$. If both places were equidistant north and south from the 45th degree of latitude, the difference would be fọnd strictly correct. Moreover, it is doubtful whether the absolute values of the divisions of the zenith sector can be so correctly determined, that it may not have, in an arch of $5^{\circ}$, a greater inaccuracy than $0^{\prime \prime} \cdot 11$; at least I consider this as much more difficult than the determination of the declination of a star to $z^{\prime \prime}$.

This method is peculiarly recommendable on account of its independence of any error in the instrument. If the collimation should not be sufficiently corrected, the cylinders of the axis should be unequal in their diameter, the telescope or the axis should bend, \&c., we shall still obtain a correct result, either by reversing the axis between the two operations, or by observing one day in one position and the next in the other position of the 
the axis, and taking the mean of both. The success solely depends on the quality of the telescopes and the care employed in the levelling of the axis. It also appears to me that those astronomical amateurs who possess but indifferent instruments for the measuring of angles, would thus obtain a determination of their latitude with greater certainty by means of a small and portable transit-instrument, even if it were not more powerful than the common telescopes in the small repeating circles. This method, in its application for the determination of declinations under the supposition of the latitude being known, has the advantage of being quite independent of the refraction; but it can only be employed for stars north of the equator.

What ought to render this method still more interesting to you is, that your famous countryman Olaus Römer (who in his ideas of astronomical observations and instruments has surpassed many of our moderns) employed, 120 years ago, a transit instrument placed from east to west, which is described in Horrebow's works, vol. iii. pp. 228-240, and who assigns the imperfection of the instrument as the reason for its not having been subsequently employed for the observation of declinations.-The work just alluded to, which I obtained but a few weeks ago, contains so many excellent things of Römer, that $I$ am inclined to consider it as one of the most important works on practical astronomy; and I take this opportunity to observe how much might have been done in the art of observing, éven in Römer's time, if the path he took had not been again abandoned.

[Note by the Editor.-The work here alluded to by M. Bessel is entitled "Petri Horrebowii, Opera Mathematico-physica." Hauniæ, 1740,3 vols. quarto. The third volume contains the following treatise: "Basis Astronomiæ, sive Astronomiæ pars mechanica, in qua describuntur observatoria, atque instrumenta astronomica Rœmeriana Danica; simulque eorundem Usus, sive Methodi observandi Rœmerianæ." The xviii $^{\text {th }}$ chapter of this treatise is entitled " $\mathrm{De}$ instrumento Fquinoctiorum Rœmeri :" and this is the instrument alluded to by M. Bessel.

But the use of a special instrument, for the purposes here alluded to, is now superseded by the introduction of the altitude and azimuth instrument; which seems peculiarly adapted for observations of this kind.

If the circle be placed exactly east and west, we shall have $\cot \varphi=\cot \delta \cdot \cos \frac{1}{2}\left(\mathbf{T}^{\mathrm{N}}-\mathrm{T}\right)$

where $\left(\mathrm{T}^{\prime}-\mathrm{T}\right)$ denotes the correct interval of sidereat time elapsed between the two observations, expressed in degrees, \&c. But, if $\left(\mathbf{T}^{\prime}-\mathbf{T}\right)$ be taken in mean solar time, we must multiply it by 1.0027379 in order to reduce it to sidereal time.] 